\title{
Conceptualising and measuring mental fitness: A Delphi study
}

\author{
Paula Robinson · Lindsay G. Oades · Peter Caputi
}

\begin{abstract}
Despite the increased use of the term mental fitness in the popular and psychological literature, there is little consensus in relation to theory, definition and measurement. The concept of mental fitness could be used to parsimoniously engage, educate and promote proactive, positive mental health activities to the wider community, without stigma and within a language that is easily understood. This Delphi study engaged an international expert panel $(n=25)$ to evaluate a definition and four guiding principles of mental fitness. Expert consensus was achieved supporting the definition and four guiding principles with suggested modifications.

The final definition of mental fitness is "the modifiable capacity to utilise resources and skills to flexibly adapt to challenges or advantages, enabling thriving". The final four guiding principles are (1) fitness is a positive term without connotations of illness implied by mental health or mental illness; (b) mental fitness could be understood by the wider community in a similar way to physical fitness; (c) mental fitness is measurable; and (d) mental fitness can be improved, in a similar way to physical fitness. The panel also offered valuable recommendations for future research and practice.
\end{abstract}

Keywords: fitness, mental fitness, physical fitness, positive mental health

\section{Introduction}

Mental fitness is not a new concept in the psychological literature. McCarthy (1964) suggested the concept was a solution to the following plea written by the distinguished behavioural scientist and public health expert Dr Andie Knutson (1963):

"Positive mental health has been left on the doorstep of the public and professional community as a neglected and starving stepchild...it would be useful to have some new term to replace positive mental health...that retains the good will and enthusiastic participation of members of the mental health profession and their medical, health and welfare colleagues, and yet effectively elicits the involvement of members of the social sciences" (pp. 303-304).

McCarthy (1964) suggested the concept of mental fitness to express Knutson's positive mental health concept. She asked the Committee on Mental Health Research Programs of the APA "to try it on for size and see how well it fits" (p. 201). Further, McCarthy suggested utilising the term mental fitness for President Kennedy's population based fitness program by combining mental and physical fitness initiatives i.e., a total fitness solution. 


\subsection{Why mental fitness?}

The Positive Psychology literature (e.g., Seligman \& Csikszentmihalyi, 2000; Seligman, 2008) supports Knutson's proposition and confirms that a scientific understanding of positive mental health and effective interventions are important for building thriving individuals and communities. Whilst Seligman (2002) explains that the general stance of Positive Psychology is prevention, he confirms there is very little focus on how to educate, promote and engage the wider community in proactive positive mental health activities. Keyes (2007) whilst agreeing with the need to prevent illness, also argues for a need to promote positive mental health, and uses the term flourishing. Keyes suggests there are economic and social advantages for a paradigm shift towards mental health promotion to work in conjunction with mental illness prevention. He argues that if most government strategies for mental health continue to focus on diagnosed mental illness alone, the best that can be hoped for is a reduction in the level of diagnosed mental illness. Moreover, this approach does not assure a mentally healthy population, suggesting that mental health is a separate continuum whereby 'a languishing individual' can function at levels similar to someone with a major depressive episode i.e., diagnosed as neither mentally ill nor mentally healthy. This view is consistent with the World Health Organisation's (WHO) evidence paper on mental health promotion (see Naidoo \& Wills, 2000) which states that health can mean the absence of disease or disability but, just as often, may refer to a state of fitness or to a reservoir of personal resources that can be called upon when needed. Further, WHO suggest that health promotion supports personal and social development and emphasises the importance of positive mental health education and practices for their own sake as well as for prevention and treatment.

The challenge is how to further engage and motivate the wider community to not only become proactive in their own positive mental health strategies and activities, but to sustain them. It is suggested here that a more familiar framework underpinned by research and delivered via an easy to understand language that is not stigmatised is needed. Notwithstanding numerous anti-stigma campaigns in western nations, there remains conceptual confusion and stigma surrounding many psychological concepts because the concepts suggest that there is something wrong with the person. For example, "mental health" is often used interchangeably with "mental illness". This is not the case with the term "physical health" and "physical illness". The term "physical fitness goes further by being viewed as a process of achieving optimal physical health. So one solution to overcome some of the stigma would be to revisit McCarthy's proposition to utilise the term mental fitness as a process of achieving optimal mental health.

At a foundational level and as is the case in the development of physical fitness, achieving higher levels of mental fitness would require motivation. It is useful to employ well-developed and evidenced-based theories to support such an endeavour. Research from self-determination theory suggests that the innate human needs of autonomy, competence and relatedness facilitate higher levels of motivation and provide the basic components for human growth and development. Conversely, if these needs are thwarted an unsuccessful response is probable (see Deci \& Ryan, 1985, 2000; Sheldon, 2002; Baard, Deci \& Ryan, 2004). Therefore, consideration of these basic psychological needs would be important to any mental fitness model and subsequent interventions.

The concept of mental fitness could also be incorporated as a component of health-related or total fitness. The American College of Sports Medicine (ACSM, 2000) support the definition of 'health-related fitness' developed by Pate (1988) who defines fitness as the demonstration of capacities that help prevent disease and promote health. 
The conceptualisation of mental fitness must be a coherent combination of theory, research and practice and utilising the physical fitness analogy would have relevance to the wider community. To commence the process, a review by Robinson, Oades and Caputi (2014) suggests there is evidence that the term mental fitness is being increasingly utilised to engage and promote positive mental health strategies and practices. In summary, the term fitness was reviewed by charting the historical, popular and psychological literature. To understand how prevalent the term fitness is for the English speaking, general population of the 21st century, the popular search was performed on Google, revealing a large number of search engine results depending on the term searched; fitness 461 million results, physical fitness 86 million, mental fitness over 17 million and physical/mental fitness together revealed more than 6 million results.

An analysis examined the first 50 pages for each group and the content was allocated to a category. This allocation to a category was most often made using the information available on the Google search page and also by viewing the source website to determine the exact nature of the site. The primary categories were then calculated by frequency; the first category contained pages that appeared to the researchers to be information reflecting a reputable genre e.g. health and psychological services; the second category contained less reliable sources, e.g. individuals without qualifications, private blogs, social media, etc.; the third category was specifically advertising courses and programs from multiple sources; the fourth category contained either government or non-government organisations; and finally there was a media category containing pages where the terms appeared in published material, e.g. magazines.

The psychological literature was analysed via a PsycInfo search extending from 1879 to 2013 which revealed a total of 60 results, consisting of peer-reviewed journals and books. Despite the relatively small number of results from the psychological literature, there were a number of related and frequent themes that emerged from the analysis which were congruent with the historical and popular searches, for example, (a) mental and physical health and fitness often appear together and involve intentional, learned, skills that are changeable via regular exercises to practise; (b) evolutionary theory, the processes of adaptation and natural selection; (c) mental fitness has cognitive, affective and behavioural components; (d) mental fitness can be domainspecific, that is, work, home, and social; (e) it is a process with wellbeing outcomes; (f) mental fitness has capacity to use psychological resources, e.g. resilience; (g) mental fitness may also assist in the reduction of some mental illnesses, e.g. anxiety, anger and depression; (h) there are treatment and prevention components; (i) there are numerous mental fitness tests and indicators but they vary in explanation and content.

Overall, the results suggest that 'mental fitness' is a widely used term, particularly in the popular literature, and is being utilised in much the same way as is the term 'physical fitness'. All search results revealed similar language and ideas across the historical, popular and psychological literature. The meaning of the term mental fitness suggests it is a process towards functioning at optimal levels, and that it is holistic, goal-orientated, adaptive, intentional and developmental. Individuals are active agents in the process of becoming mentally fit and have the ability or capacity to adapt and respond to enable them to move towards a successful fit between themselves and their environment.

Further, mental fitness (like physical fitness) is viewed as important to mental health and can be learned; indeed the primary focus in the popular and psychological literature is exercise and training. However, central findings in the review is a lack of consistent theoretical and empirical foundations, that there is no consensus on a definition and there are no reliable and valid measurement instruments of mental fitness for scientific investigation or for practitioners to apply. 
Based on the above results, a preliminary definition and four guiding principles for the development of the concept of mental fitness were constructed for consideration and evaluation by an international panel of experts in the field of psychology and positive psychology using the Delphi technique (see summary below):

\section{The definition}

Mental fitness is the changeable capacity to utilise resources and skills to psychologically adapt to environmental challenges or advantages to meet psychological needs.

Key terms within the definition of mental fitness were based on the literature review, which suggested mental fitness is changeable, captures capacity, utilises learned resources/skills, is adaptable, and relates to environmental challenges (or advantages) and requires motivation to participate in regular, intentional activities. It is important to note that the meaning of the term 'adapt' in the context of mental fitness is drawn from the Encyclopaedia of Positive Psychology (Lopez, 2009) which states "adaptability is the capacity to adjust oneself readily to fit changed circumstances".

In summary, the definition suggests that a mentally fit person has a reserve of psychological resources and skills that can be readily utilised to increase the probability of a successful response to a negative stressor or an opportunity. Further, it suggests that a mentally fit person would be expected to have high self-awareness and self-regulation to elicit a psychologically flexible response (e.g., Kashdan \& Rottenberg, 2010).

\subsection{Principle 1}

Fitness is a positive term without connotations of illness implied by mental health or mental illness.

Principle 1 is based on the assumption that the term physical health is understood by individuals and the wider community as absence of physical disease, without stigma. Conversely, the term mental health is understood as absence of mental illness but is largely stigmatised. Stigma is a crucial issue as noted by a comprehensive review of the literature led by Cheverton (2009). The review supports the notion that the stigma attached to mental ill-health prevents most people from disclosing it. The review suggests that the longer people leave seeking help, the more significant their ultimate call on health and social services will be. Thus the underlying assumption of Principle 1 suggests that the term fitness is easily understood by the wider community and it is essentially a positive term that is not stigmatised.

\subsection{Principle 2}

Mental fitness could be understood by individuals, organisations, educational institutions and the wider community in a similar way to physical fitness.

Physical fitness is defined by Corbin, Pangrazi and Franks (2000) as a set of attributes relating to the ability to perform physical activity that people have or achieve, and by Microsoft Encarta's entry on Physical Fitness (2004) as a combination of qualities that enable us to be at our full potential in performing vigorous physical activities and involve (but are not limited to) strength, flexibility and endurance. The term mental fitness employs metaphor, transposing components from one context to another e.g., mental strength, flexibility and endurance. These terms would be useful for ease of explanation and application for mental health practitioners and the wider community. Table 1 below shows a conceptual example of a resource index containing positive 
mental health constructs proposed by Robinson, Oades and Caputi, (2014), utilising the physical fitness framework.

Table 1: Conceptual example of a mental fitness resource index

\begin{tabular}{cl}
\hline & Self-efficacy \\
Strength & Positive affect ratio \\
& Social support \\
& Emotional management \\
\hline \multirow{3}{*}{ Flexibility } & Mindfulness \\
& Acceptance \\
& Psychological flexibility \\
\hline \multirow{2}{*}{ Endurance } & Resilience \\
& Meaning \\
& Purpose \\
& Hope \\
\hline
\end{tabular}

In summary, Principle 2 suggests that physical fitness is already understood in the wider community as a strategy for illness prevention and is associated with optimal physical functioning. For example, cardiac fitness achieved through exercise assists in lowering heart attacks and mortality rates (e.g., Blair et al., 1996). Therefore, the term mental fitness would be a more positive concept to communicate mental health initiatives to individuals, schools, organisations and the community because it uses an established language and framework that is positive, parsimonious, preventative, proactive and easily understood. Moreover, it is possible to articulate mental fitness activities and practices aligned to physical fitness to create a total fitness solution - physical and mental being of equal importance for wellbeing and optimal functioning.

\subsection{Principle 3}

\section{Mental fitness is measurable}

Principle 3 suggests that the operationalising of a mental fitness model would first require the building of a resource index. Components of a resource index would consist of evidence-based psychological variables that are developmental, changeable and understood as being a part of a proactive and preventative approach to positive mental health. There are a number of psychological theories, measures and interventions that have converging characteristics of individuals who are considered to be functioning well. For example, Warner and Vroman (2011) found that specific behaviours predict improvements in wellbeing. An evidence-based resource index would also assist in synthesising key theories, research and activities within the psychological literature relating to positive mental health that remain largely disconnected.

\subsection{Principle 4}

Mental fitness can be improved in a way similar to physical fitness.

Principle 4 suggests that mental fitness can be learned via developmental activities, exercises and regular practice to 'fit' assessed needs. Evidence in positive psychology and the neural plasticity literature suggests the brain has the ability to change and adapt as a result of experience and learning new behaviours throughout life. Neuroscientist Davidson (2005) found via functional 
magnetic resonance imaging (FMRI) analysis that individuals could regulate their emotions if they were well practiced (also see meta-analyses of Greenwood \& Parasuraman, 2010; Sin and Lyubormirsky, 2009). A meta-analysis by Bolier et al. (2013) also found that positive psychology intervention activities increase both subjective and psychological wellbeing outcomes. Diener and Biswas-Diener (2008), in their discussions on psychological wealth, include engaging activities as part of the process of improving wellbeing.

Following the conceptual review and preliminary formulation of a definition and four guiding principles, the next step to develop the concept and measurement of mental fitness is to have the definition and principles evaluated by a global panel of experts utilising the Delphi technique.

\section{Method}

\subsection{Research design}

The Delphi method is useful for evaluating definitions, new concepts and for gathering of knowledge and opinions (Adler \& Ziglio, 1996; Buccini, Jones, Iverson \& Caputi, 2009; Mullen \& Gold, 1988). For example, it has been used to identify problems (Yell, Deno, Marston, 1992), investigate theoretical and practical issues (Fish \& Piercy, 1987), predict trends (Cramer, 1991), identify components of mental disorders (Morrison \& Barratt, 2010) and investigate areas that have not been articulated clearly or explored widely (Weatherman \& Swenson, 1974).

The Delphi process provides researchers with a systematic methodology to organise responses and ideas that can be developed further into theory, models and measurement (Linstone \& Turoff, 1975; Merriam, 1998). Moreover, it provides an efficient and effective way to involve busy experts who may not be able to come together to interact with each other to investigate theoretical and practical issues and ultimately build consensus.

Typically, in a Delphi study, a set of criteria is formulated to use when choosing an expert panel to ensure all members have expertise in the specific domain being investigated. Martino (1972) recommends that the expert panel be made up of between 15 and hundreds of panellists. However, Somers, Baker and Isbell (1984) suggest that small panels are more advantageous because small panels reduce the complexity of data analysis. Panel opinions are gathered by conducting two or three rounds of communication and the group response on the final round is used to represent group consensus (Grissom \& Cochran 1986). According to McElreath (2001), key summary steps are necessary to conduct an effective Delphi study. McElreath's steps were followed throughout this study. A guiding assumption of the Delphi technique is that consensus of the expert panel's opinion is a good predictor of future practices (Weatherman \& Swenson, 1974).

\subsection{Procedure}

This study consisted of four phases as summarised in Figure 1 below.

\subsubsection{Phase 1: Participants}

Lopez and Rogers (2001) suggest two of five specific criteria be applied to select the expert panellists. To further ensure panel expertise, participants were chosen if they met three of the following five criteria:

1) Author criteria - Panellist must have at least three primary or secondary author publications related to psychological growth and development; 
2) Presenter criteria - Panellist must have made two or more presentations at nationally or internationally respected conferences on topics relating to psychological growth and development;

3) Academic criteria - Panellist must be an academic in the field of Psychology and hold a doctoral degree;

4) Practice criteria - Panellist must be a practicing psychologist registered for more than ten years and currently working with clients on a regular basis;

5) Positive psychology criteria - Panellist must be specifically published in the sub-field of Positive Psychology or teaching it in an academic setting.

Each panellist was allocated a code to provide anonymity throughout the study. This also ensured a more objective evaluation of each other's comments and ideas without attaching any one comment to a particular person. Given many of the panellists have high profiles in their field of expertise, anonymity also controlled for any (conscious or unconscious) bias by other panellists based on knowledge of the authors or their work (see Appendix 1 for a summary of expert panel criteria).

Figure 1: Delphi study method summary flowchart

Selection of criteria for Delphi Panel recruitment \& send out requests.
Phase 2: Round 1 request
Phase 3: Round 1 results \& round 2 request
Panel receive quantitative and qualitative results. Panel is requested to
agree, disagree, or provide a neutral response and comment for each
response.
Phase 4: Final consensus
Consensus results are formulated based on \% of
principles

\subsubsection{Phase 2: Round 1 request}

Following completion of Phase 1, Round 1 Request was distributed by email to all expert panellists. The requests contained a Participant Information Sheet, steps in the study, an explanation of the Delphi process, an abstract and specific questions (see example question in Figure 2) relating to the initial definition and four guiding principles of mental fitness. Whilst the development of the definition and principles were completed, Round 1 deliberately gave minimal information about the development of the definition and the four principles to the 
expert panel. The reason for this approach was twofold: (a) given their expert knowledge, it was important to allow the panel to respond to questions without too much background information to influence or bias their initial responses; thus their responses were based on their own knowledge alone and not given to them by the researchers; (b) to ensure the panel focussed on the specifics of the questions only and not on the justification of how they were formed. The panel consisted of experts in Psychology with expert knowledge based on strict criteria set in Phase 1, therefore, an important goal of the study was to have panellists respond based on their own knowledge and experience.

There were five major questions in the study. The following example illustrates the qualitative and quantitative components of each question:

\section{Figure 2: Example question}

The definition provided was "the changeable capacity to utilise resources and skills to psychologically adapt to environmental challenges or advantages to meet psychological needs".

Generally, I agree/disagree with the definition of Mental Fitness

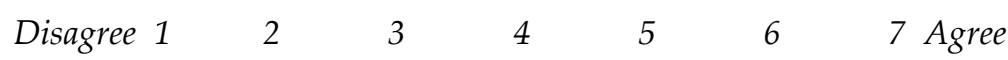

(Neutral)

Below, please write any specific comments or ideas on the definition

(in less than 100 words)

Question 1 asked panellists to rate their level of agreement to comment on the definition of mental fitness. Panellists were also supplied with summary explanations for key terms within the definition and what these key terms might mean in relation to a mentally fit person (see Appendix 2). For example, the summary explanation for the term:

Capacity - a mentally fit person has a reserve of psychological resources and skills that could be readily deployed to improve the probability of an adaptive response to a negative stressor or a favourable circumstance or advantage.

This part of the study gave the panellists the opportunity to comment on specific terms in the qualitative section and also allowed them to either agree or disagree on the overall definition in the quantitative section.

Questions 2 to 5 asked the panel to rate their agreement/disagreement and comment on each of the four guiding principles of mental fitness:

Principle 1: "Fitness is a positive term without connotations of illness implied by mental health or mental illness".

Principle 2: "Mental fitness could be understood by individuals, organizations, educational institutions and the wider community in a similar way to physical fitness".

Principle 3: "Mental Fitness is measurable".

Principle 4: "Mental Fitness can be improved in a way similar to physical fitness". 
As in question 1, each principle had a brief summary explanation (see Appendix 2).

\subsubsection{Phase 3: Round 1 results to panel and round 2 request}

In Round 2 a Participant Information Sheet, an abstract, method and qualitative and quantitative response results from Round 1 were forwarded to panellists via email. In this second round, panellists were asked to rate and comment on each other's specific Round 1 responses for the definition and each of the four guiding principles of mental fitness. As this was the first time the panel viewed each other's responses, they were asked to agree or disagree with other panellists' suggestions or ideas with no response being treated as neutral. Panellists were also asked to note at the end of each question, any additional elaborations, suggestions or ideas based on the other panellists' qualitative responses.

\section{Results}

\subsection{Round 1}

The final pool of twenty-five panellists was primarily drawn from Australia, the United Kingdom and the United States. Other countries represented in the study included Demark, Canada and New Zealand. Fifteen panellists were males and ten were females. Analysis shows that of the twenty-five respondents, $88 \%$ met author criterion, $88 \%$ met the presenter criterion, $80 \%$ met the academic criterion, $52 \%$ met practice criterion and $64 \%$ met the Positive Psychology criterion (see detail in Appendix 1).

\subsubsection{Round 1 - Quantitative results}

All twenty-five expert panellists completed Round 1. Averages were calculated across all panellist response items on a 7-point Likert scale. Table 2 below shows, mean, standard deviation, mode and median for all five questions. Results suggest a high level of agreement for the proposed definition and each of the four guiding principles of mental fitness. Principle 4 shows the highest level of agreement and the lowest variability.

Table 2: Descriptive statistics

\begin{tabular}{|c|c|}
\hline Generally, I agree/disagree with ... & Level of agreement \\
\hline $\begin{array}{l}\text { The Definition } \\
\text { "Mental fitness is the changeable capacity to utilise resources and skills to } \\
\text { psychologically adapt to environmental challenges or advantages to meet } \\
\text { psychological needs". }\end{array}$ & $\begin{array}{l}(\mathrm{M}=5.54, \mathrm{SD}=1.44) \\
\mathrm{Mo}=6, \mathrm{Md}=6\end{array}$ \\
\hline $\begin{array}{l}\text { Principle } 1 \\
\text { "Fitness is a positive term without connotations of illness implied by mental } \\
\text { health or mental illness". }\end{array}$ & $\begin{array}{l}(\mathrm{M}=5.88, \mathrm{SD}=1.69) \\
\mathrm{Mo}=7, \mathrm{Md}=6\end{array}$ \\
\hline $\begin{array}{l}\text { Principle } 2 \\
\text { "Mental fitness could be understood by individuals, organizations, } \\
\text { educational institutions and the wider community in a similar way to } \\
\text { physical fitness". }\end{array}$ & $\begin{array}{l}(\mathrm{M}=5.83, \mathrm{SD}=1.59) \\
\mathrm{Mo}=6, \mathrm{Md}=6\end{array}$ \\
\hline $\begin{array}{l}\text { Principle } 3 \\
\text { "Mental Fitness is measurable". }\end{array}$ & $\begin{array}{l}(\mathrm{M}=5.64, \mathrm{SD}=1.02) \\
\mathrm{Mo}=5, \mathrm{Md}=6\end{array}$ \\
\hline
\end{tabular}


Principle 4

"Mental Fitness can be improved in a way similar to physical fitness".
$(\mathrm{M}=6.54, \mathrm{SD}=0.72)$,

$\mathrm{Mo}=6, \mathrm{Md}=6$.

\subsubsection{Round 1 - Qualitative results}

Members of the panel were asked to "write any specific comments or ideas on the definition and the 4 principles of Mental Fitness (in less than 100 words)". The qualitative responses from all panellists were reviewed for inclusion in Round 2. Tables 3 to 7 show all responses that were included in Round 2. Examples of qualitative comments not included in Round 2 were:

1) Panel responses where they generally agreed without offering any suggestions or changes to the definition or principles, for example:

a) "I think that this is an excellent definition. The five key terms elaborate on the concept very well. I also like the way that mental fitness may be compared with physical fitness in such a way that the lay person can easily relate to".

b) "Yes, this is particularly appealing and the field of brain plasticity gives ample evidence that this is possible. It is also inherently attractive in the same way in which physical fitness is linked to health and well-being."

2) Panellists who generally disagreed but did not include any suggestions or changes, to the definition or principles, for example:

a) "Yes and no; can be learned if you have the right coach."

b) "No-I don't think it is a term that is widely used."

In summary, the purpose of Round 1 was to (a) quantitatively assess whether the expert panel agreed or disagreed with the definition and each of the four guiding principles of mental fitness and (b) to offer suggestions/ideas for improvement. Quantitative results suggest a high level of agreement. Ideas put forward by the panel were collated and the results evaluated by the expert panel in Round 2.

\subsection{Phase 4 - Round 2 results: Consensus for definition and four guiding Principles}

Twenty-two panellists responded to Round 2 by the deadline set by the researchers. The task for Round 2 was for the expert panel to respond to the qualitative suggestions/ideas proposed in Round 1 (see summary responses in Tables 3 to 7 ). The panel's response range consisted of "yes I agree", "no I disagree" and "neutral". Blank responses indicating the respondents did not hold a strong view either way were not calculated in the results. For the purpose of this study, all responses were calculated and if less than 20\% disagreed and more than $51 \%$ agreed, the definition or principle was changed according to the expert panel's recommendation (Buccini, et al., 2009). Tables 3 to 7 summarise the expert panel's feedback.

Summary of results from Table 3 below show the expert panel recommended the following changes to the definition of mental fitness: (a) internal and external challenges are both viewed as important, therefore, the term challenges remains with the word environmental being removed; (b) some members questioned the use of the term changeable, implying that it is too general. Whilst the term flexible was mentioned as an alternative, this is not appropriate in relation to capacity. The term capacity is utilised here to refer to the size of the resources and skills available, not the nature of the resource itself. Therefore, the adjective flexible is added before the word adapt; (c) further, as the panel considered the term changeable as not being clear, this has also been considered. For this reason, the word modifiable has been chosen to replace the word changeable. Whilst the two terms are similar, modifiable is more specific than is changeable, by implying limits 
to the change, and that the change is primarily intentional, i.e., it can increase or decrease, it can be trained, in a similar manner to physical fitness; and (d) replacing psychological needs with the term thriving. Thus the revised definition is as follows:

"Mental fitness is the modifiable capacity to utilise resources and skills to flexibly adapt to challenges or advantages, enabling thriving".

\section{Table 3: Qualitative responses for definition}

The Definition: "Mental fitness is the changeable capacity to utilise resources and skills to psychologically adapt to environmental challenges or advantages to meet psychological needs".

"Changeable" or perhaps "flexible" capacity?

"Not clear what you mean by 'changeable' capacity. Is this where the flexibility and ability to respond with an appropriately adaptive response is implied?"

"Stressors/challenges are not always external but can often involve internal dialogue and selfperceptions...personal (and interpersonal) stressors/factors seem relevant and deserve specific reference."

"The term 'environmental' to me implies that challenges or advantages can only be external to the individual. Would a lack of confidence in being able to do well in a job interview, for example, not be recognised as some sort of challenge for an individual to overcome?"

"Mental fitness meets more than just psych needs, so perhaps this part is rather limiting....this is a sort of baseline achievement, but actually that mental fitness could help us go a lot beyond this and into the domain of true mental flourishing."

"Meeting needs may imply survival, while flourishing or thriving refers to enjoying full potential... It may not capture the notion of flourishing or thriving."

Summary of results from Table 4 below shows Principle 1 remained unchanged with the panel suggesting it could be (a) measured on a continuum and (b) that mental fitness is a process with mental health and wellbeing as outcomes.

Table 4: Qualitative responses for Principle 1

Principle 1: "Fitness is a positive term without connotations of illness implied by mental health or mental illness".

"Yes, mental fitness should be asset based, in other words that a person possesses certain desirable qualities rather than does not possess certain undesirable qualities."

"Recently, mental health is also defined in terms of the presence of psychological well-being. Therefore, to further clarify the distinction between mental fitness and mental health, the former should be focusing on the process while the latter should focus on the outcome. In other words, mental fitness will imply the ability to achieve wellbeing and prevent or reduce mental illness."

"Fitness is also understood in a biological sense as in "survival of the fittest", and the fitness of a species for a particular environment. Hans Selye's original research on stress spoke of fitness as a determinant of the stress response."

"There is overwhelming empirical and theoretical reasons to believe that almost all well-being and human functioning is on a continuum (e.g. from anxiety to calmness). Focussing on only a positive or negative pole is one of the greatest weaknesses of psychology today. In the present case, there will be a continuum from low to high level of fitness, and only focusing on the positive poll is neither scientifically justifiable or logical."

"I really like the term fitness and yes it does get away from negative connotations. It can be measured on a continuum as you can have different levels of fitness and gives the opportunity for some development and growth." 
"Psychological fitness should be understood as the presence of positive qualities, not the absence of negatives."

Summary of results from Table 5 below for Principle 2 shows the panel recommended organisational references be deleted but supported using the concepts of physical and mental fitness (total fitness) together to convey meaning to the wider community. Principle 2 was revised as follows:

"Mental fitness could be understood by the wider community in a similar way to physical fitness".

Table 5: Qualitative responses for Principle 2

Principle 2: "Mental fitness could be understood by individuals, organizations, educational institutions and the wider community in a similar way to physical fitness".

"Not just illness prevention, but also wellness promotion."

"My one concern would be using it in an organisational setting. It is not a term that I think managers would be able to use about an individual due to the points that I raised regarding possible connotations. I am not sure who in an organisation would be able to use this term in an organisational context without there being a potential danger of legality over the term. In an organisational context, I know words such as 'tough mindedness' have started to be accepted but I would be concerned about passing judgement or discussing the mental fitness of employees."

"Although there are differences between physical and mental fitness I think that there are enough similarities to quickly and easily convey the meaning of the term to the broader community. Hopefully this will also serve to strengthen the connection between mind and body, as the scientific separation of the two really makes very little practical sense."

"Plenty of evidence from the sports and endurance literature I'm sure that links physical and mental toughness."

"I reiterate my comments above for principle 1. It gives scope for growth, change and is developmental by nature; not fixed at any point in time."

"Total fitness could also include the concepts of stability (being calm, centred and confident) as well as speed (improvising and intuitive)."

"Perhaps the general community would think that mental fitness had something to do with intelligence or being smart at school. It would be important to stress that mental fitness would apply to any age, just not young who were also physically fit and it may be hard to separate the two images of physical and mental fitness. Could an older person be physically challenged but still mentally well or could a younger person be very fit but depressed?"

Summary of results from Table 6 below for Principle 3 suggest it remains unchanged but with the panel recommending:

1) Components of strength, flexibility and endurance need a specific definition;

2) Components of strength, flexibility and endurance will need rigorous scientific investigation;

3) Self-report is viewed as limiting and specific components of mental fitness may be difficult to measure. The panel suggested consideration of an objective measure.

4) A further recommendation is to investigate the relationship of strengths and mental fitness. 
Table 6: Qualitative responses for Principle 3

Principle 3: "Mental fitness is measurable".

"I like the fact that an individual who practices most of the key principle psychology interventions may develop mental fitness as defined here. For example, individuals who have identified their strengths and use them in the service of something bigger than themselves may develop strength (self-efficacy), flexibility (acceptance), and endurance (meaning)."

"Generally agree with this, although I think there are a number of ways you could cut this data. Would also be interested to see where strengths use specifically fits into this construct, as something that is associated with a wide range of positive correlates."

"It would be helpful to have a definition of the terms to aid understanding. It might also make more sense to indicate if a component builds strength, flexibility or endurance, as I imagine that there is cross over between them."

"I think it would be useful to operationalize exactly what you mean by strength, flexibility, and endurance."

“Would need a bit more information about how 'strength', 'flexibility' and 'endurance' are defined within mental fitness; not entirely sure that the resource index components' are specific to the three domains."

"At some point you will need to explain why the different descriptors have been put into these categories."

"I agree that in principle it is measurable, but care needs to be taken with whether it is measurable through self-report - mindfulness has been, though this has been widely criticised and the findings are not comparable with objective measures. Similarly, this is a major problem with the VIA - what does self-reported sense of humour actually mean? Particularly when we know that people have enhancement biases where most people think that they are better than average (see Sedikides' work in this area)."

"Clearly some aspects of mental fitness are easy to measure. But like in physical fitness there are dimensions which are difficult to measure, dimensions like mindfulness, meaning or purpose seem to me very difficult to measure."

Summary results for Table 7 below for Principle 4 suggest it remains unchanged but with the panel recommending:

1) Caution when drawing parallels that are too close to physical fitness, as they may differ across variables;

2) The need to study individual differences;

3) Activities could be developed to work simultaneously on mental and physical fitness;

4) Design research to show how mental fitness differs from other interventions;

5) Motivation to improve may be less given there is no clinical diagnosis;

6) The development of a set of targeted activities based on proper assessment. 


\section{Table 7: Qualitative responses for Principle 4}

\section{Principle 4: "Mental fitness can be improved in a way similar to physical fitness".}

"I totally subscribe to this view that mental fitness can be learned and developed. See for example Fred Luthan's work on psychological capital which seems to follow a similar principle. I would be cautious about drawing the parallels too closely with physical fitness, since there may come a point where the parallel breaks down and ultimately constrains you in terms of your thinking and also how you present mental fitness to a wider audience. Just something to be aware of."

"As an example, reading Todd Kashdan's book on curiosity has made me more curious, which has made me more mentally fit I would argue so yes."

"I think that you can definitely improve mental fitness through training and exposure to mental exercises. I have observed people improve specific aspects of mental fitness such as: Strengths, Positivity and Hope. The only piece I wonder is if everyone can increase mental fitness, like physical fitness there maybe individual differences between people. There might also be a small percentage of people who are unable to increase their mental fitness." "Yes learned (taught) and caught from experiences - including failure - so that personal construing is possible. I feel that growth mindset research (Dweck) is key to understanding how this process can be delivered, largely from reflection.

"Nice concept but for me it conjures up the notion that physical and mental health are dichotomous concepts. I think the real skill would be to develop activities that simultaneously work on mental and physical fitness. The two systems are interdependent. After I return from a good workout at the gym, I think more clearly, rationally and positively. I am sure some psychological interventions that work on self-appreciation and gratitude (e.g. for good health and life) would encourage more physically and healthy lifestyles."

"Strength, flexibility and endurance seem to be useful conceptual categories for communicating the meaning of mental fitness, but I am unsure about their utility beyond that. It would be helpful to have definitions of these terms to better understand how they could be targeted."

"Yes, this is particularly appealing and the field of brain plasticity gives ample evidence that this is possible. It is also inherently attractive in the same way in which physical fitness is linked to health and well-being."

"Mental fitness interventions will target the components of strength, flexibility, and endurance. The theoretical underpinnings of any interventions specific to the components of 'mental fitness' will have to be compared to a cognitive behavioural intervention, compared to a self-determination theory intervention, compared to an emotional intelligence theory (compared to placebo/control). If you are very specific with the language to describe the construct, construct factors, measurement, and the potential theoretical underpinning for applied interventions, then construct validation will also be systematic."

"If clinical psychologists did not believe that a trained clinician could not increase a person's well-being (from below normal to normal), then one wonders what their mission is. Similarly, positive psychology interventions should effectively increase a person's well-being (from normal, or just below normal, to above normal). However one has to acknowledge that average motivation to change may be less in the latter situation, as immediate suffering is not a driver."

"I'm not sure about the degree to which mental fitness is learned and increased in the same way that physical fitness is achieved. I would predict a more complex set of precursors in terms of prior emotional/psychological learning that may interact with the 'mental fitness program' and thus need to be 'targeted'. However, I endorse the idea of having a set of targeted activities and exercises based on proper assessment that would lead to increased levels of mental fitness. My questions would be around such things as is there a neat set of exercises to take a person from self-doubt to self-belief'. Will the parallels of 'physical and mental fitness' hold up across some variables, and not so well with others?"

\section{Discussion}

The reason for undertaking this Delphi study was to address the conceptual confusion and to commence the process of developing the concept and subsequent measurement of mental fitness. This study proposed an initial definition and four guiding principles drawn from a conceptual review and current theory. The results suggest acceptable levels of consensus were reached by the international expert panel for the definition and four guiding principles of mental fitness. 
Quantitative results suggest the panel generally agreed with the definition and each of the four guiding principles. Qualitative results also suggest general agreement, with minor modifications and further provided constructive recommendations based on the level of agreement set by the researchers. Specifically, the definition of mental fitness was updated to be "the modifiable capacity to utilise resources and skills to flexibly adapt to challenges or advantages, enabling thriving". Principles 1, 3 and 4 remained unchanged. The panel recommended Principle 2 be modified to "mental fitness could be understood by the wider community in a similar way to physical fitness".

Numerous useful suggestions and insights were put forward by the panel as summarised in the results section. For example, the panel suggested that mental fitness could be viewed as a process whilst mental health and wellbeing could be viewed as an outcome thus inferring that scientifically evaluated mental fitness practices and activities could achieve improved levels of wellbeing and assist in preventing or reducing mental illness. From a biological perspective, the term 'survival of the fittest' was noted in relation to Hans Selye's research on stress and fitness as a determinant of the stress response. These suggestions (and others detailed in Tables $3-7$ ) concur with the conceptual review previously conducted. The components of Self-Determination Theory (autonomy, competence, relatedness) were viewed by the panel as an important component of wellbeing but limiting, the panel suggested the concepts of thriving and flourishing were more important within the definition. Overall, the results of this Delphi study suggest that the concept and principles of mental fitness were understood and generally accepted by the panel as an endeavour worthy of scientific exploration. Further, the concept of mental fitness was viewed as a positive and effective strategy that can assist in the promotion of mental health activities to improve levels of health and wellbeing within the wider community.

\section{Limitations}

The results presented in this study do not mask the complex nature of defining, measuring and improving mental fitness. The process is both a creative and scientific undertaking. This Delphi study has provided valuable feedback but was based on only two rounds: the study may have benefited from a third round designed to give the panel an opportunity to collaborate further. Whilst the Delphi method provides a systematic approach, in-depth discussion and final input is limited by the predetermined cut-offs. Another limitation is that the sub-components of strength, flexibility and endurance were not fully defined and each will require further investigation.

\subsection{Future directions and implications}

The expert panel made numerous constructive recommendations for future research and practice. For example, members of the panel suggested mental fitness could be measured on a continuum and emphasised the need to explore the nature of individual differences and levels of motivation in the absence of a clinical diagnosis. By consensus, the panel also suggested that strengths could be a specific area of research to ascertain their relationship to mental fitness. Panellists also suggested the need for research designed to compare differences with other positive mental health interventions. A further recommendation was that a mental fitness strategy can create the opportunity to develop community-based programs and panellists suggested that mental fitness activities could be developed to simultaneously work on mental and physical fitness. Such activities must address targets based on accurate assessment.

The panel stressed the importance of developing both self-report and performance based measures as is the case with physical fitness assessment. Because there is a paucity of studies that 
have investigated how positive mental health activities and practices might interact together in a more holistic way, the panel also suggested exploring components of a mental fitness model to determine combinations that serve as good predictors of thriving individuals.

There are also broader questions to be answered, longitudinal studies would be useful in answering them. For example, what happens when people engage in mental health practices and activities regularly over an extended period of time? What would change if people felt more comfortable talking about their mental fitness in a way similar to how they talk about physical fitness?

More broadly, the panel suggested that an alignment to the physical fitness analogy provides a preventative and proactive approach that can be easily understood by the community and without stigma and therefore a worthy field of study. The rationale to commence investigating a mental fitness concept is driven by the need for new and novel approaches to mental health and the increasing but inconsistent use of the term in the psychological and popular literature, which is limiting both research and practice. There is a need for more research on what mental fitness is and what it is not to develop a cohesive theoretical framework, a standardised operational definition, and reliable and valid measures for future research, replication and practical application.

\author{
Authors \\ Paula Robinson \\ University of Wollongong \\ paula@positivepsyhologyinstitute.com.au \\ Lindsay G. Oades \\ University of Wollongong \\ Peter Caputi \\ University of Wollongong \\ Publishing Timeline \\ Received 25 October 2013 \\ Accepted 2 June 2014 \\ Published 26 January 2015
}

\title{
References
}

Adler, M., \& Ziglio, E. (1996). Gazing into the Oracle: The Delphi Method and its Application to Social Policy and Public Health. London: Jessica Kingsley Publishers.

American College of Sports Medicine (2000). ACSM's guidelines for exercise testing and prescription (6th ed), Baltimore, MD: Lippincott, Williams Watkins.

Baard, P. P., Deci, E. L., \& Ryan, R. M. (2004). Intrinsic need satisfaction: A motivational basis of performance and well-being in two work settings. Journal of Applied Social Psychology 34, 2045-2068. http://dx.doi.org/10.1111/j.1559-1816.2004.tb02690.x

Bolier, L., Haveman, M., Westerhof, G. J., Riper, H., Smith, F. \& Bohlmeijer, E. (2013). Positive psychology interventions: a meta-analysis of randomized controlled studies. BMC Public Health, 13, 119-139. http://dx.doi.org/10.1186/1471-2458-13-119

Buccini, L.D., Jones, C., Iverson, D., \& Caput, P.. (2009). Toward a construct definition of informed consent comprehension. Journal of Empirical Research Ethics, 4, 17-23.

http://dx.doi.org/10.1525/jer.2009.4.1.17 
Blair, S. N., Kampert, J. M., Kohl, H. W., Barlow, C. E., Macera, C. A., Paffenbarger, R. S., Gibbons, L. W. (1996). Influences of cardiorespiratory fitness and other precursors on cardiovascular disease and allcause mortality in men and women. Journal of the American Medical Association, 276, 205-210. http://dx.doi.org/10.1001/jama.1996.03540030039029

Cheverton, J. Queensland Alliance (2009). From discrimination to social inclusion. A review of the literature on anti stigma initiatives in mental health.

http://www.qldalliance.org.au/sites/www.qldalliance.org.au/files/news/2010/07/341689-upload00001.pdf.

Corbin, C. B. Pangrazi, R. P. \& Franks, B. (2000). Definitions: Health, fitness and physical activity. President's Council on Physical Fitness and Sports, Washington DC.

Cramer, R. H. (1991). The education of gifted children in the United States: A Delphi study. Gifted Child Quarterly, 35, 84-91. http://dx.doi.org/10.1177/001698629103500207

Davidson, R. J. (2005). Emotion regulation, happiness, and the neuroplasticity of the brain. Advances in Mind-Body Medicine, 21, 25-58.

Diener, E., \& Biswas-Diener, R. (2008). The science of optimal happiness. Boston: Blackwell Publishing.

Deci, E. L., \& Ryan R. M. (1985). Intrinsic motivation and self-determination in human behavior. New York: Plenum. http://dx.doi.org/10.1007/978-1-4899-2271-7

Deci, E. L., \& Ryan. R. M. (2000). The "what" and "why" of goal pursuits: Human needs and the selfdetermination of behavior. Psychological Inquiry, 4, 227-268. http://dx.doi.org/10.1207/S15327965PLI1104 01

Fish, L. S., \& Piercy, F. P. (1987). The theory and practice of structural family therapies: A Delphi study. Journal of Marital and Family Therapy, 13, 113-125. http://dx.doi.org/10.1111/j.1752-0606.1987.tb00690.x

Greenwood, P.M., \& Parasuraman, R. (2010). Neuronal and cognitive plasticity: a neurocognitive framework for ameliorating cognitive aging. Frontiers in Aging Neuroscience, 2, 1-14. http://dx.doi.org/10.3389/fnagi.2010.00150

Grissom, B. W., \& Cochran, S. W. (1986). Critical competencies for teachers of hearing-impaired students: The practitioners' view. American Annals of the Deaf, 131, 267-270. http://dx.doi.org/10.1353/aad.2012.0748

Kashdan, T. B., \& Rottenberg, J. (2010). Psychological flexibility as a fundamental aspect of health. Clinical Psychological Review, 30, 865-878. http://dx.doi.org/10.1016/j.cpr.2010.03.001

Keyes, L. M. (2007). Promoting and protecting mental health as flourishing. American Psychologist, 62, 95108. http://dx.doi.org/10.1037/0003-066X.62.2.95

Knutson, A. L. (1963). New perspectives regarding positive mental health. American Psychologist, 18, 300306. http://dx.doi.org/10.1037/h0048445

Linstone, H. A., \& Turoff, M. (1975). Introduction to the Delphi method: techniques and publications in H. A., Linstone \& M. Turoff (Eds), The Delphi Method: Techniques and applications. Boston: AddisonWesley Publishing Company.

Lopez, S. (2009). The encyclopedia of positive psychology. New York: Wiley-Blackwell.

Lopez, E. C., \& Rogers, M. R. (2001). Conceptualizing cross-cultural school psychology competencies. School Psychology Quarterly, 16, 270-302. http://dx.doi.org/10.1521/scpq.16.3.270.19889

Martino, J. P. (1972). Technological forecasting for decision-making. New York: Elsevier.

McCarthy, D. (1964). Mental Fitness. American Psychologist, 19, 201-202.

McElreath, M. (2001). Managing systematic and ethical public relations programs, cited Nehiley, J.M. (2001). How to conduct a Delphi study. New York: Wiley.

Merriam, S. B. (1998). Qualitative research and case study applications in education. San Francisco: JosseyBass.

Morrison, A. P., \& Barratt, S. (2010). What Are the Components of CBT for Psychosis? A Delphi Study. Schizophrenia Bulletin, 36, 136-142. http://dx.doi.org/10.1093/schbul/sbp118

Mullen, K. D., Gold, R.S. (1988). Wellness construct delineation: a Delphi study. Health Education Research, 3, 353-366. http://dx.doi.org/10.1093/her/3.4.353

Naidoo J., \& Wills J. (2000). Health promotion: Foundations for practice. Edinburgh, Harcourt Publishers. 
Pate, R. (1988). The evolving definition of physical fitness. Quest, 40, 174-179. http://dx.doi.org/10.1080/00336297.1988.10483898

Physical Fitness (2004). Microsoft Encarta (version 2.1 Software). Redmond, WA: Microsoft Corporation.

Robinson, P. L., Oades, L. G., \& Caputi, P. (2014). Conceptualising and measuring mental fitness. Ph.D. Thesis. University of Wollongong: Australia.

Seligman, M. E. P. (2002). Positive psychology, positive prevention, and positive therapy. In C. R. Snyder \& S.J. Lopez (Eds.), The handbook of positive psychology (pp. 3-12). New York: Oxford Press.

Seligman, M. E. P. (2008). Positive Health. Applied psychology, 57, 3-18. http://dx.doi.org/10.1111/j.14640597.2008.00351.x

Seligman, M. E. P., \& Csikzentmihalyi, M. (2000). Positive psychology: An introduction. American Psychologist, 55, 5-14. http://dx.doi.org/10.1037/0003-066X.55.1.5

Sheldon, K. M. (2002). The self-concordance model of healthy goal-striving: When personal goals correctly represent the person. In E.L. Deci \& R. M. Ryan (Eds), Handbook of self-determination research (pp. 65-86). Rochester, NY: University of Rochester Press.

Sin, N. L., \& Lyubomirsky, S. (2009). Enhancing well-being and alleviating depressive symptoms with positive psychology interventions: A practice-friendly meta-analysis. Journal of Clinical Psychology: In Session, 65, 467-487. http://dx.doi.org/10.1002/jclp.20593

Somers, K., Baker, G., \& Isbell, C. (1984). How to use the Delphi technique to forecast training needs. Performance and Instruction Journal, 23, 26-28. http://dx.doi.org/10.1002/pfi.4150230412

Warner, R. M., \& Vroman, K. G. (2011). Happiness inducing behaviors in everyday life: An empirical assessment of 'the how of happiness'. Journal of Happiness Studies, 12, 1063-1082. http://dx.doi.org/10.1007/s10902-010-9245-3

Weatherman, R., \& Swenson, K. (1974). Delphi technique. In S. P. Hencley \& J. R. Yates (Eds.), Futurism in education: Methodologies (pp. 97-114). Berkeley, CA: McCutchan.

Yell, M. L., Deno, S. L., \& Marston, D. B. (1992). Barriers to implementing curriculum-based measurement. Diagnostique, 18, 99-114. 


\section{Appendix 1: Summary of expert panel criteria}

\begin{tabular}{|c|c|c|c|c|c|}
\hline $\begin{array}{l}\text { PANELLIST } \\
\text { NUMBER }\end{array}$ & $\begin{array}{l}\text { AUTHOR } \\
\text { CRITERIA }\end{array}$ & $\begin{array}{l}\text { PRESENTER } \\
\text { CRITERIA }\end{array}$ & $\begin{array}{l}\text { ACADEMIC } \\
\text { CRITERIA }\end{array}$ & $\begin{array}{l}\text { PRACTICE } \\
\text { CRITERIA }\end{array}$ & $\begin{array}{c}\text { POSITIVE PSYCHOLOGY } \\
\text { CRITERIA }\end{array}$ \\
\hline 1 & $\mathrm{X}$ & $\mathrm{X}$ & $\mathrm{X}$ & $\mathrm{X}$ & \\
\hline 2 & $\mathrm{X}$ & $\mathrm{X}$ & $\mathrm{X}$ & & $\mathrm{X}$ \\
\hline 3 & $\mathrm{X}$ & $\mathrm{X}$ & $\mathrm{X}$ & $\mathrm{X}$ & \\
\hline 4 & $\mathrm{X}$ & $\mathrm{X}$ & $\mathrm{X}$ & & $X$ \\
\hline 5 & $\mathrm{X}$ & $\mathrm{X}$ & $X$ & $X$ & $\mathrm{X}$ \\
\hline 6 & $\mathrm{X}$ & $\mathrm{X}$ & & $\mathrm{X}$ & $\mathrm{X}$ \\
\hline 7 & $\mathrm{X}$ & $\mathrm{X}$ & $\mathrm{X}$ & $\mathrm{X}$ & $\mathrm{X}$ \\
\hline 8 & $\mathrm{X}$ & $\mathrm{X}$ & $X$ & & $\mathrm{X}$ \\
\hline 9 & $\mathrm{X}$ & $\mathrm{X}$ & $\mathrm{X}$ & & $\mathrm{X}$ \\
\hline 10 & & & $\mathrm{X}$ & $\mathrm{X}$ & $\mathrm{X}$ \\
\hline 11 & $\mathrm{X}$ & & $\mathrm{X}$ & & $\mathrm{X}$ \\
\hline 12 & $\mathrm{X}$ & $\mathrm{X}$ & & $\mathrm{X}$ & $\mathrm{X}$ \\
\hline 13 & $\mathrm{X}$ & $\mathrm{X}$ & $\mathrm{X}$ & $\mathrm{X}$ & $X$ \\
\hline 14 & $\mathrm{X}$ & $\mathrm{X}$ & $\mathrm{X}$ & $\mathrm{X}$ & \\
\hline 15 & $\mathrm{X}$ & $\mathrm{X}$ & $\mathrm{X}$ & & $\mathrm{X}$ \\
\hline 16 & $\mathrm{X}$ & $\mathrm{X}$ & $\mathrm{X}$ & & $\mathrm{X}$ \\
\hline 17 & $\mathrm{X}$ & $\mathrm{X}$ & & $\mathrm{X}$ & \\
\hline 18 & $\mathrm{X}$ & $\mathrm{X}$ & & $\mathrm{X}$ & \\
\hline 19 & $\mathrm{X}$ & $\mathrm{X}$ & & $\mathrm{X}$ & \\
\hline 20 & $\mathrm{X}$ & $\mathrm{X}$ & $\mathrm{X}$ & & $X$ \\
\hline 21 & $X$ & $\mathrm{X}$ & $\mathrm{X}$ & & \\
\hline 22 & $\mathrm{X}$ & $\mathrm{X}$ & $\mathrm{X}$ & & \\
\hline 23 & & $\mathrm{X}$ & $\mathrm{X}$ & $\mathrm{X}$ & $X$ \\
\hline 24 & $\mathrm{X}$ & $\mathrm{X}$ & $\mathrm{X}$ & $\mathrm{X}$ & $\mathrm{X}$ \\
\hline 25 & $\mathrm{X}$ & $\mathrm{X}$ & $\mathrm{X}$ & & $\mathrm{X}$ \\
\hline
\end{tabular}




\section{Appendix 2: Questions with summary explanations}

Q1: Generally, I agree/disagree with the Definition

"Mental fitness is the changeable capacity to utilise resources and skills to psychologically adapt to environmental challenges or advantages to meet psychological needs".

Explanation of key terms within the definition:

1) Capacity - a mentally fit person has a reserve of psychological resources and skills that could be readily deployed to improve the probability of an adaptive response to a negative stressor or a favourable circumstance or advantage.

2) Utilise Resources $\mathcal{E}$ Skills - is capacity in action. A mentally fit person will trigger capacity and use specific psychological resources and skills to improve the probability of an adaptive response.

3) Psychologically Adapt - A mentally fit person is more likely to successfully adapt when the specific resources and skills are utilised.

4) Challenges or advantages - A mentally fit person would be expected to have higher levels of self-awareness and self-regulation to elicit a psychologically flexible response dependent on the environmental challenge or advantage presented.

5) Psychological needs - A successful adaptive response would ensure the needs of Competence, Autonomy and Relatedness are being addressed.

Q2: Generally, I agree/disagree with Principle 1

Fitness is a positive term without connotations of illness implied by mental health or mental illness.

Principle 1 is generally based on the following assumptions:

1) Physical health is understood in the wider community as absence of disease.

2) Mental health is understood in the wider community as absence of mental illness and largely stigmatised.

3) Conceptual confusion exists in relation to many psychological terms causing a slowdown of mental illness prevention and optimal mental health promotion resulting in a lack of engagement by the general community. The term fitness is easily understood by the wider community and not stigmatised.

Q3: Generally, I agree/disagree with Principle 2

Mental fitness could be understood by individuals, organizations, educational institutions and the wider community in a similar way to physical fitness.

Principle 2 is generally based on the following assumptions:

1) Physical fitness is understood in the wider community as a strategy for illness prevention and associated to optimal physical functioning essentially based on levels of strength, flexibility and endurance.

2) Mental fitness could be understood in the wider community as a strategy for mental illness prevention and associated to optimal mental functioning using the same conceptual framework as physical fitness, i.e., strength, flexibility 
and endurance. Thus mental fitness could be aligned to physical fitness by way of explanation and assist in a total fitness solution, both physical and mental fitness being essential for optimal human functioning. There is a real need for a more proactive, preventative approach to mental illness and mental health promotion as we have with physical fitness.

Q4: Generally, I agree/disagree with Principle 3

Mental Fitness is measurable.

Principle 3 is generally based on the following assumptions:

The operationalising of a mental fitness construct would first require the building of a resource index. Subscales could be analogous to physical fitness i.e. strength, flexibility and endurance for parsimony and ease of explanation to the wider community.

Following a comprehensive review of the literature, an example of a resource index was offered to the panel (see Table 1).

Q5: Generally, I agree/disagree with Principle 4

Mental Fitness can be improved in a way similar to physical fitness.

Principle 4 is generally based on the following assumptions:

3) Mental fitness can be learned (activities, exercises, regular practice).

4) Mental fitness interventions could target specific components. 